\title{
Factors Affecting Purchasing Decisions at Nayla Buah (NB) Store Tebeng In Bengkulu City
}

\section{Faktor-Faktor yang Mempengaruhi Keputusan Pembelian pada Toko Nayla Buah (NB) Tebeng Kota Bengkulu}

\author{
Ayu Andri ${ }^{1)}$; Ida Anggriani ${ }^{2)}$; Nirta Vera Yustanti ${ }^{2)}$ \\ 1)Study Program of Management, Faculty of Economic, Universitas Dehasen Bengkulu \\ ${ }^{2)}$ Department of Management, Faculty of Economic, Universitas Dehasen Bengkulu \\ Email: ${ }^{1)}$ ayuandri371@gmail.com; ${ }^{2)}$ ida.anggriani26@gmail.com; ${ }^{2)}$ nirtavera22@gmail.com;
}

How to Cite :

Andri, A., Anggriani, I., Yustanti, N. V. (2021). Factors Affecting Purchasing Decisions at Nayla Buah (NB) Store Tebeng In Bengkulu City. EMAK: Jurnal Ekonomi Manajemen Akuntansi Dan Keuangan, 2(4). DOI: https://doi.org/10.53697/emak.v2i4

\section{ARTICLE HISTORY}

Received [12 Agust 2021]

Revised [25 Agust 2021]

Accepted [05 October 2021]

KEYWORDS

Culture, Social, Personal and Psychology

This is an open access article under the $C C-B Y$-SA license

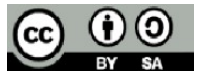

\section{ABSTRAK}

Penelitian ini bertujuan untuk mengetahui pengaruh faktor kebudayaan terhadap keputusan pembelian, faktor sosialterhadap keputusan pembelian, faktor pribaditerhadap keputusan pembelian, faktor psikologis terhadap keputusan pembelian dan untuk mengetahui pengaruh faktor kebudayaan, faktor sosial, faktor pribadi, dan faktor psikologis secarabersamaan terhadap keputusan pembelian pada toko Nayla Buah (NB) Tebeng Kota Bengkulu.Jenis penelitian ini bersifat asosiatif, penelitian yang dilakukan untuk mengetahui nilai variabel mandiri, baik satu variabel atau lebih yang bertujuan untuk mengetahui hubungan antara dua variabel atau lebih. Pelaksanaan metode yang dilakukan adalah survey. populasi dalam penelitian ini adalah sebanyak 1200 Konsumen. sampel yang mejadi responden dalam penelitian ini sebanyak 92 konsumen. Dalam pengujian validitas menggunakan Coeffisient Corelation Pearson dengan nilai signifikansi 5\% dengan nilai kritis dan Uji reabilitas berdasarkan koefisen Alpha Cronbachserta Uji hipotesis dengan menggunakan analisis regresi berganda. Hasil penelitian menunjukkan bahwa (1) Tidak terdapat pengaruh signifikan faktor budaya terhadap keputusan pembelian di Toko Nayla Buah Kota Bengkulu dengan nilai signifikansinya lebih besar dari 0,05 yaitu 0,144. (2)Terdapat pengaruh positif dan signifikan antara faktor sosial terhadap keputusan pembeliandi Toko Nayla Buah Kota Bengkulu dengan nilai signifikansinya lebih kecil daripada 0,05 yaitu 0,013. (3) Terdapat pengaruh positif dan signifikan faktor pribadi terhadap keputusan pembeliandi Toko Nayla Buah Kota Bengkulu dengan nilai signifikansinya lebih kecil dari pada 0,05 yaitu 0,030. (4) Tidak terdapat pengaruh signifikan faktor psikologi terhadap keputusan pembelian di Toko Nayla Buah Kota Bengkulu dengan nilai signifikansinya lebih besar dari 0,05 yaitu 0,432. (5) Terdapat pengaruh positif dan signifikan faktor budaya, sosial, pribadi dan psikologis terhadap keputusan pembelian di Toko Nayla Buah Kota Bengkulu dengan nilai signifikansinya sebesar 0,000 lebih kecil dari pada 0,05(6) Faktor yang mempengaruhi keputusan pembelian adalah faktor sosial dan faktor pribadi.Kata Kunci: Kebudayaan, Sosial, Pribadi dan Psikologis

ABSTRACT

This study aims to determine the effect of cultural, social, personal, and 
psychological factors on purchasing decisions and to determine the effect of all the factors simultaneously on purchasing decisions at Nayla Buah (NB) storeTebeng, Bengkulu City. This research is an associative research, which conducted to determine the value of the independent variable, one variable or more than one variables, which aims to determine the relationship between the variables. The method used is a survey. The population in this study were 1200 consumers. The sample of respondents were 92 consumers. The validity using the Pearson Coefficient Correlation with a significance value of $5 \%$ with a critical value and the reliability test based on the Cronbach Alpha coefficient and hypothesis testing using multiple regression analysis. The results showed that (1) There is no significant influence of cultural factors on purchasing decisions at Nayla Buah Bengkulu City with a significance value greater than 0.05, namely 0.144. (2) There is a positive and significant influence of social factors on purchasing decisions at Nayla Buah store with a significance value smaller than 0.05, namely 0.013. (3) There is a positive and significant influence of personal factors on purchasing decisions at Nayla Buah store with a significance value smaller than 0.05, namely 0.030. (4) There is no significant effect of psychological factors on purchasing decisions at Nayla Buah store with a significance value greater than 0.05, namely 0.432. (5) There is a positive and significant influence of cultural, social, personal and psychological factors on purchasing decisions at Nayla Buah store with a significance value of 0.000 which is smaller than 0.05. (6) The factors that influence purchasing decisions are social and personal factors.

\section{PENDAHULUAN}

Toko Nayla Buah (NB) adalah salah satu dari sekian banyak toko yang menjual berbagai jenis buah-buahan. Toko Nayla (NB) buah ini juga termasuk toko buah yang sangat ramai diminati oleh konsumen. Toko Nayla Buah (NB) menjual berbagai macam jenis buah-buahan seperti jeruk, buah naga, kelengkeng, mangga, melon, anggur, apel, semangka, dan lain sebagainya dengan harga ecer maupun grosir. Selain menjual buah-buahan Toko Nayla Buah (NB) ini juga menjual berbagai olahan buah seperti salad buah, buah potong dan menerima jasa pembuatan parcel buah, dll.Toko Nayla Buah (NB) ini cukup berkembang, selain karena harganya yang terjangkau, Toko Nayla Buah (NB) ini juga menjual buah-buahan dengan tingkat harga dan kualitas buah yang berbeda, mulai dari harga yang paling rendah, menengah, bahkan harga yang paling tinggi, sesuai dengan kualitas buah.

Toko Nayla Buah (NB) ini pada awalnya memiliki dua ruko dan sekarang berkembang menjadi tiga ruko. Toko Nayla Buah (NB) selalu ramai dikunjungi oleh pembeli pada setiap harinya, dan minat beli pada Toko Nayla Buah (NB) cukup tinggi. Menurut Priansa (2016:164) Minat Pembelian adalah pemusatan perhatian terhadap suatu yang disertai dengan perasaan senang terhadap barang tersebut, kemudian minat individu tersebut menimbulkan keinginan sehingga timbul perasaan yang meyakinkan bahwa barang tersebut mempuyai manfaat sehingga individu ingin memiliki barang tersebut dengan cara membelinya.

Toko Nayla Buah (NB) ini terletak di Jl. Dempo Raya, Tebeng Kota Bengkulu. Dengan lokasinya yang sangat strategis berada dipinggir jalan raya dengan lahan parkir yang cukup luas sehingga aman bagi konsumen nya untuk menempatkan kendaraannya. Toko Nayla Buah (NB) ini berada di tengah kota dan dekat dengan kampus Dehasen, sekolah, kantor-kantor dan masyarakat sekitar, yang memungkinkan sebagai salah satu alternatifnya.

Keberadaan konsumen mempunyai pengaruh pada pada Toko Nayla Buah (NB) untuk mencapai tujuannya, yaitu perolehan laba melalui pembelian produk. Untuk menjalankan usahanya Toko Nayla Buah (NB) harus mengetahui faktor-faktor yang mempengaruhi konsumen dalam pengambilan keputusan pembelian. Menurut Kotler (2015:203) Ada empat Faktor yang 
mempengaruhi perilaku konsumen yaitu faktor budaya, faktor sosial, faktor pribadi dan faktor psikologis. Oleh karena itu Toko Nayla Buah (NB) harus mengetahui apa saja strategi yang harus diterapkan pada tokonya untuk menarik konsumen baru dan mempertahankan konsumen tetap yang sudah berlangganan pada tokonya. Yang menjadi salah satu hal yang menarik peneliti untuk melakukan penelitian pada toko ini adalah Toko Nayla Buah (NB) semakin berkembang dan selalu ramai dikunjungi oleh para konsumen setiap hari.

\section{LANDASAN TEORI}

\section{Manajemen Pemasaran}

Manajemen pemasaran merupakan alat analisis, perencanaan, penerapan, dan pengendalian program yang dirancang untuk menciptakan, membangun, dan mempertahankan pertukaran yang menguntungkan dengan target pasar sasaran dengan maksud untuk mencapai tujuan utama perusahaan yaitu memperoleh laba. Manajemen Pemasaran menurut Assauri (2013:12), adalah “Manajemen pemasaran merupakan kegiatan penganalisisan, perencanaan, pelaksanaan, dan pengendalian program-program yang dibuat untuk membentuk, membangun, dan memelihara keuntungan dari pertukaran melalui sasaran pasar guna mencapai tujuan organisasi (perusahaan) dalam jangka panjang".Menurut Tjiptono (2011:2), manajemen pemasaran merupakan sistem total aktivitas bisnis yang dirancang untuk merencanakan, menetapkan harga, dan mendistribusikan produk, jasa dan gagasan yang mampu memuaskan keinginan pasar sasaran dalam rangka mencapai tujuan organisasional.

American Marketing Association, menterjemahkan pemasaran sebagai berikut: Pemasaran adalah pelaksanaan dunia usaha yang mengarahkan arus barang-barang dan jasa-jasa dari produsen ke konsumen atau pihak pemakai. Defenisi ini hanya menekankan aspek distribusi ketimbang kegiatan pemasaran. Philip Kotler dalam bukunya Marketing Management Analysis, Planning, and Control, mendefinisikan pemasaran secara lebih luas, yaitu: Pemasaran adalah: Suatu proses sosial, dimana individu dan kelompok mendapatkan apa yang mereka butuhkan, dan mereka inginkan dengan menciptakan dan mempertahankan produk dan nilai dengan individu dan kelompok lainnya. Definisi Pemasaran menurut William J. Stanton adalah suatu sistem keseluruhan dari kegiatan-kegiatan bisnis yang ditujukan untuk merencanakan, menentukan harga, mempromosikan, dan mendistribusikan barang dan jasa yang memuaskan kebutuhan baik kepada pembeli yang ada maupun pembeli potensial. Sunarto (2016:16) mengemukakan bahwa manajemen pemasaran ialah sebagai analisis, perencanaan, implementasi dan pengendalian dari program-program yang di rancang untuk menciptakan, membangun dan memelihara pertukaran yang menguntungkan dengan pembeli sasaran untuk mencapai tujuan perusahaan.

\section{Produk}

Kotler (2015:212) mengemukakan bahwa produk adalah "segala sesuatu yang dapat ditawarkan kepasar untuk menarik perhatian, dimiliki, digunakan atau dikonsumsi yang dapat memuaskan keinginan dan kebutuhan". Sedangkan menurut Lamb (2017:414) "produk didefinisikan sebagai segala sesuatu yang baik yang menguntungkan maupun tidak yang diperoleh seseorang melalui pertukaran".Dari definisi diatas dapat disimpulkan bahwa produk adalah segala sesuatu baik barang maupun jasa yang dapat digunakan dan dinikmati yang memiliki nilai untuk dipasarkan untuk memenuhi keinginan dan kebutuhan seseorang.

\section{Perilaku Konsumen}

Perilaku konsumen menyangkut masalah keputusan yang diambil seseorang dalam persaingannya dan penentuan untuk mendapatkan dan mempergunakan barang dan jasa. Perilaku konsumen menurut Mowen (2017:6) mengatakan: "Studi tentang unit pembelian (buying unit) dan 
proses pertukaran yang melibatkan perolehan, konsumsi dan pembuangan, barang, jasa, pengalaman serta ide-ide".

\section{Keputusan Pembelian}

Menurut Engel,dkk (2015:45) "Perilaku konsumen adalah tindakan yang langsung terlibat dalam mendapatkan, mengkonsumsi serta menghabiskan produk dan jasa, termasuk proses keputusan yang mendahului dan menyusuli tindakan ini". Adapun Keputusan Pembelian menurut Engel (2015:45) adalah proses merumuskan berbagai alternatif tindakan guna menjatuhkan pilihan pada salah satu alternatif tertentu untuk melakukan pembelian. Menurut Assauri (2015:139) keputusan pembelian yang dilakukan oleh konsumen dipengaruhi pula oleh kebiasaan. Dalam kebiasaan pembelian mencakup kapan waktunya pembelian dilakukan, dalam jumlah berapa pembelian tersebut dilaksanakan, dan dimana pembelian tersebut dilakukan.

\section{Faktor-Faktor Yang Mempengaruhi Keputusan Pembelian}

Menurut Kotler (2015:144), Keputusan pembelian dipengaruhi oleh faktor kebudayaan, faktor sosial, faktor pribadi, dan faktor psikologis. Berikut adalah faktor-faktor yang mempengaruhi keputusan pembelian:

1. Faktor Kebudayaan

Kebudayaan merupakan penentu keinginan dan perilaku yang peling mendasar untuk mendapatkan nilai, persepsi, preferensi dan perilaku dari lembaga-lembaga penting lainnya. Faktor kebudayaan memberikan pengaruh paling luas dan dalam pada tingkah laku konsumen.

2. Faktor Sosial

Kelas sosial merupakan pembagian masyarakat yang relatif homogen dan permanen yang tersusun secara hierarkis dan yang anggotanya menganut nilai-nilai, minat dan perilaku yang serupa.

3. Faktor Pribadi

Faktor pribadi didefinisikan sebagai karakteristik psikologis seseorang yang berbeda dengan orang lain yang menyebabkan tanggapan yang relative konsisten dan bertahan lama terhadap lingkungan.

4. Faktor PsikologisFaktor psikologis sebagai bahan dari pengaruh lingkungan dimana ia tinggal dan hidup pada waktu sekarang tanpa mengabaikan pengaruh dimasa lampau atau antisipasinya pada waktu yang akan datang.

\section{Peran Konsumen Dalam Membeli}

Menurut Engel, et all (2015:31), keputusan pembelian adalah proses merumuskan berbagai alternatif tindakan guna menjatuhkan pilihan pada salah satu alternatif tertentu untuk melakukan pembelian. pemasar perlu mengetahui siapa yang terlibat dalam keputusan membeli dan peran apa yang dimainkan oleh setiap orang untuk banyak produk, cukup mudah untuk mengenali siapa yang mengambil keputusan. Menurut Engel, et all (2015:33) beberapa peran dalam keputusan membeli:

1. Pemrakarsa: orang yang pertama menyarankan atau mencetuskan gagasan membeli produk atau jasa tertentu.

2. Pemberi pengaruh: orang yang pendangan atau sarannya mempengaruhi keputusan membeli.

3. Pengambil keputusan: orang yang akhirnya membuat keputusan membeli atau sebagian dari itu, apakah akan membeli, apa yang dibeli, bagaimana membelinya atau dimana tempat membeli.

4. Pembeli: orang yang benar-benar melakukan pembelian.

5. Pengguna: orang yang mengkonsumsi atau menggunakan produk atau jasa. 
Jenis-Jenis Dan Tingkah Laku Keputusan Pembelian

Menurut Kotler (2015:160) Semakin kompleks keputusan yang harus diambil biasanya

semakin banyak pertimbangannya untuk membeli. Adapun jenis-jenis tingkah laku membeli

konsumen berdasarkan pada derajat keterlibatan dan tingkat perbedaan antara merek, yaitu:

1. Tingkah laku membeli yang kompleks

2. Tingkah laku membeli yang mengurangi ketidak cocokan

3. Tingkah laku membeli yang merupakan kebiasaan

4. Dalam hal ini, tingkah laku konsumen tidak diteruskan lewat urutan keyakinan, sikap, tingkah laku yang biasa. Konsumen tidak mencari informasi secara ekstensif mengenai produk mana yang akan dibeli.

5. Karena membeli tidak memberikan komitmen yang kuat pada suatu merek, pemasar produk yang kurang terlibat pada beberapa perbedaan merek seringkali menggunakan harga dan promosi penjualan untuk merangsang konsumen agar mau mencoba produk.

6. Tingkah laku membeli yang mencari variasi, konsumen menjalani tingkah laku membeli yang mencari variasi dalam situasi yang ditandai oleh keterlibatan konsumen rendah, tetapi perbedaan merek yang dianggap berarti.

\section{METODE PENELITIAN}

\section{Metode Analisis}

Regresi Linier Berganda

Penelitian ini menggunakan uji regresi berganda. Regresi berganda (multivariate regression) merupakan suatu model di mana variabel terikat tergantung pada dua atau lebih variabel bebas. Regresi berganda digunakan untuk mengetahui pengaruh variabel bebas terhadap variabel terikat. Rumus regresi berganda pada penelitian ini yaitu (Sugiyono, 2016:192) :

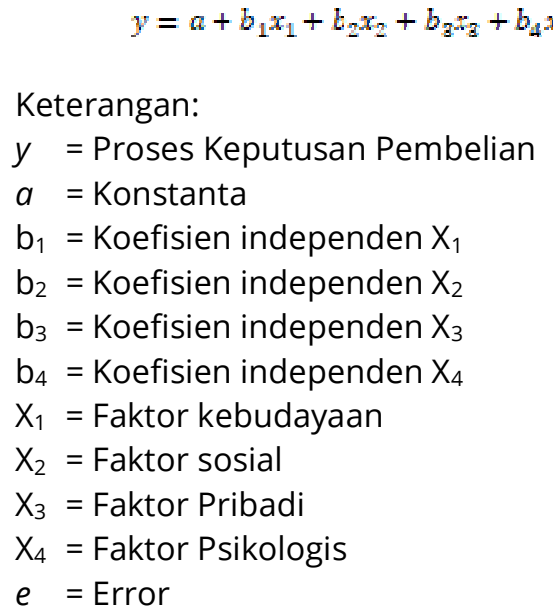

\section{Koefisien Determinasi $\left(\boldsymbol{R}^{2}\right)$}

$\mathrm{R}$ adalah koefisien korelasi majemuk yang mengukur tingkat hubungan antara variabel dependen $(Y)$ dengan semua variabel independen yang menjelaskan secara bersama-sama dan nilainya selalu positif. Selanjutnya untuk melakukan pengujian koefisien determinasi (adjusted $\mathrm{R}^{2}$ ) digunakan untuk mengukur proporsi atau presentase sumbangan variabel independen yang diteliti terhadap variasi naik turunnya variabel dependen. Koefisien determinan berkisar antara nol sampai dengan satu $\left(0 \leq R^{2} \leq 1\right)$. Hal ini berarti bila $R^{2}=0$ menunjukkan tidak adanya pengaruh antara variabel independen terhadap variabel dependen, bila adjusted $\mathrm{R}^{2}$ semakin besar mendekati 1 menunjukkan semakin kuatnya pengaruh variabel independen terhadap variabel dependen dan bila 
adjusted $\mathrm{R}^{2}$ semakin kecil bahkan mendekati nol, maka dapatdikatakan semakin kecil pula pengaruh variabel independen terhadap variabel dependen.Adapun pedoman untuk memberikan interprestasi koefisien korelasi atau seberapa besar pengaruh variabel-variabel bebas (Independent) terhadap variabel terikat (Dependent), digunakan pedoman yang dikemukakan oleh Sugiyono (2013:250) seperti dijelaskan dalam tabel dibawahini.

Tabel 1. Pedoman Interpretasi Koefisien Korelasi

\begin{tabular}{|l|l|}
\multicolumn{1}{|c|}{ Interval Koefisien } & \multicolumn{1}{c|}{ Tingkat Hubungan } \\
\hline $0,00-0,199$ & SangatLemah \\
\hline $0,20-0,399$ & Lemah \\
\hline $0,40-0,599$ & Sedang \\
\hline $0,60-0,799$ & Kuat \\
\hline $0,80-1,000$ & SangatKuat \\
\hline
\end{tabular}

Sumber : Sugiyono (2013:250)

Uji t

Untuk menguji hipotesis tersebut digunakan statistik t yang dihitung dengan cara sebagai berikut:

$\mathrm{t}=\frac{b}{5 b}$

Sugiyono (2016:230)

Keterangan:

$b=$ nilai parameter

$\mathrm{sb}=$ standart error dari b

Standart error dari masing-masing parameter dihitung dari akar varians masing-masing. Untuk mengetahui kebenaran hipotesis digunakan kriteria bila t hitung $>\mathrm{t}$ tabel maka Ho ditolak dan Ha diterima, artinya ada pengaruh antara variabel bebas terhadap variabel terikat dengan derajat keyakinan yang digunakan sebesar $\mathrm{a}=5 \%$, begitu pula sebaliknya bila $\mathrm{t}$ hitung $<\mathrm{t}$ tabel maka Ho diterima dan Ha ditolak artinya tidak ada pengaruh antara variabel bebas terhadap variabel terikat.

\section{Uji F}

Uji F dilakukan untuk megetahui pengaruh variabel bebas secara bersama-sama terhadap variabel terikat. Rumusan hipotesis yang diuji:

1. Ho:b1=b2=b3=b4=b5=0, berarti secara bersama-sama tidak ada pengaruh variabel bebas terhadap variabel teikat

2. $\mathrm{Ha}: \mathrm{b} 1 \neq \mathrm{b} 2 \neq \mathrm{b} 3 \neq \mathrm{b} 4 \neq \mathrm{b} 5 \neq 0$, berarti secara bersama-sama ada pengaruh variabel bebas terhadap variabel teikat

Untuk alternatif dilakukan uji $\mathrm{F}$ dengan rumus sebagai berikut:

$$
F=\frac{\mathrm{g}^{2} / k}{\left(1-R^{2}\right)(n-h-1}
$$

Sugiyono (2016:235)

Bila $\mathrm{F}$ hitung > F tabel maka Ho ditolak dan Ha diterima, artinya rumus variabel bebas secara bersama-sama merupakan penjelas yang signifikan tehadap variabel terikat. Bila $F$ hitung $<\mathrm{F}$ tabel maka Ho diterima dan Ha ditolak, artinya semua variabel bebas secara bersama-sama bukan merupakan variabel penjelas yang signifikan terhadap variabel terikat. 


\section{HASIL DAN PEMBAHASAN}

Hasil dan Pembahasan

Regresi Linier Berganda

Metode Regresi linier berganda Analisis untuk mengetahui pengaruh faktor budaya, faktor sosial, faktor pribadi dan faktor psikologi terhadap keputusan pembelian dilakukan dengan bantuan software SPSS 26 . Besarnya pengaruh yang ditimbulkan oleh faktor kebudayaan, faktor sosial, faktor pribadi dan faktor psikologi diduga mempengaruhi keputusan pembelian konsumen dijabarkan pada tabel dibawah ini.

Tabel 2 .Rangkuman hasil penelitian

\begin{tabular}{|l|l|l|}
\hline Regresi & Uji t & Uji f \\
X1 Faktor Budaya & 0,114 & \\
X2 Faktor Sosial & 0,013 & 0,000 \\
X3 Faktor Pribadi & 0,030 & \\
X4 Faktor Psikologis & 0,432 & \\
\hline Koefisien Determinasi & 0,255 \\
\hline
\end{tabular}

Sumber :Hasil Penelitian dan Data Diolah, 2020

Dari tabel diatas dapat dilihat nilai-nilai hasil uji yang telah dilakukan dalam penelitian ini.

1. Faktor Kebudayaan Tidak BerpengaruhTerhadap Keputusan Pembelian di Toko Nayla Buah Kota Bengkulu

Hasil penelitian menunjukkan bahwa faktor kebudayaan tidak berpengaruh terhadap keputusan pembelian di Toko Nayla Buah Kota Bengkulu. Hal ini dibuktikan darinilai signifikansi sebesar 0,114 > 0,05 maka dapat dikatakan faktor kebudayaan tidak mempunyai pengaruh signifikan terhadap keputusan pembelian pada Toko Nayla Buah (NB) Tebeng Kota Bengkulu.

2. Faktor Sosial BerpengaruhTerhadap Keputusan Pembelian di Toko Nayla Buah Kota Bengkulu Faktor Sosial memiliki arah hubungan positif terhadap keputusan pembelian di toko Nayla Buah kota Bengkulu. Selanjutnya dari hasil penelitian diperoleh nilai signifikansi faktor sosial sebesar 0,013 lebih kecil dari 0,05 Berarti dapat disimpulkan faktor sosial mempunyai pengaruh signifikan terhadap keputusan pembelian pada Toko Nayla Buah (NB) Tebeng Kota Bengkulu.

3. Faktor Pribadi BerpengaruhTerhadap Keputusan Pembelian di Toko Nayla Buah Kota Bengkulu Faktor Pribadi memiliki nilai signifikan sebesar 0,030 $<0,05$ Berarti faktor sosial (X2) mempunyai pengaruh signifikan terhadap keputusan pembelian (Y) pada Toko Nayla Buah (NB) Tebeng Kota Bengkuluhal ini menunjukkan bahwa faktor pribadi memiliki arah hubungan positif terhadap keputusan pembelian di Toko Nayla Buah Kota Bengkulu. Berarti dapat disimpulkan bahwa Ha diterima dan $\mathrm{H}_{0}$ ditolak yang berbunyi faktor sosial mempunyai pengaruh signifikan terhadap keputusan pembelian pada Toko Nayla Buah (NB) Tebeng Kota Bengkulu.

4. Faktor Psikologis BerpengaruhTerhadap Keputusan Pembelian di Toko Nayla Buah Kota Bengkulu

Berdasarkan hasil SPSS pengaruh faktor psikologi terhadap keputusan pembelian diperoleh nilai signifikansi sebesar 0,432>0,05. Dengan demikian dapat disimpulkan bahwa tidak ada pengaruh yang signifikan antara faktor psikologis (X4) terhadap perilaku konsumen $(\mathrm{Y})$.

5. Faktor Budaya, Sosial, Pribadi, dan Psikologi Berpengaruh Terhadap Keputusan Pembelian di Toko Nayla Buah Kota Bengkulu

Faktor budaya, sosial, pribadi, dan psikologis berpengaruh terhadap keputusan pembelian di Toko Nayla Buah. Hal ini dibuktikan dengan hasil statistik uji f faktor kebudayaan, sosial, pribadi, dan psikologi diperoleh nilai signifikansi sebesar 0,000 lebih kecil dari 0,05 $(0,000<0,05)$, maka model regresi bisa dipakai untuk memprediksi keputusan pembelian konsumen atau faktor 
kebudayaan, sosial, pribadi dan psikologi secara simultan (bersama-sama) berpengaruh secara statistik terhadap keputusan pembelian konsumen.

\section{KESIMPULAN DAN SARAN}

Kesimpulan

1. Dari hasil penelitian ini dapat ditarik kesimpulan bahwa ada 4 faktor yang secara garis besar mempengaruhi tingkat penjualan serta keputusan pembelian buah-buah di toko nayla buah yaitu fator budaya, sosial, pribadi dan psikologi

2. Faktor kebudayaan tidak berpengaruh signifikan terhadap keputusan pembelian di Toko Nayla Buah Kota Bengkulu dengan nilai signifikansinya lebih besar dari 0,05 yaitu 0,144.

3. Faktor sosial mempunyai pengaruh positif dan signifikan terhadap keputusan pembelian di Toko Nayla Buah Kota Bengkulu nilai signifikansinya lebih kecil dari pada 0,05 yaitu 0,013.

4. Faktor pribadi mempunyai pengaruh positif dan signifikan terhadap keputusan pembelian di Toko Nayla Buah Kota Bengkulu dengan nilai signifikansinya lebih kecil dari pada 0,05 yaitu 0,030.

5. Faktor psikologis tidak berpengaruh signifikan terhadap keputusan pembelian di Toko Nayla Buah Kota Bengkulu dengan nilai signifikansinya lebih besar dari 0,05 yaitu 0,432.

6. Faktor budaya, sosial, pribadi, dan psikologis berpengaruh terhadap keputusan pembelian di Toko Nayla Buah. Hal ini dibuktikan dengan hasil statistik uji f faktor kebudayaan, sosial, pribadi, dan psikologi diperoleh nilai signifikansi sebesar 0,000 lebih kecil dari 0,05 $(0,000<0,05)$.

7. Faktor yang mempengaruhi keputusan pembelian adalah faktor sosial dan faktor pribadi.

\section{Saran}

1. Hasil penelitian menunjukkan bahwa variabel yang mendapatkan skor terendah adalah faktor sosial dengan indikator peran dan status sosial yang hanya mampu mengumpulkan skor sebanyak 298, karena keterbatasan peneliti untuk meneliti lebih dalam penyebabnya maka disarankan untuk peneliti selanjutnya untuk melakukan penelitian lebih dalam menyangkut variabel faktor sosial ini.

2. Diharapkan agar Toko Nayla Buah menjaga citra atau pandangan yang baik terhadap Toko Nayla Buah dengan memberikan pelayanan yang baik terhadap konsumen dan menjaga mutu produk (buah dan produk olahan buah) dengan kualitas yang baik hal ini dilakukan dengan harapan agar Toko Nayla Buah dapat mempertahankan pelanggan yang sudah lama berlangganan. Dari hasil penelitian ini menunjukkan bahwa pada masa pandemic covid 19 yang berbelanja di Toko Nayla Buah merupakan pelanggan lama dan tetap, hal ini ditunjukkan dari hasil kuesioner karakteristik responden berdasarkan lama berlangganan di dominasi oleh pelanggan dengan kategori sudah berlangganan 3 sampai dengan 4 tahun.

\section{DAFTAR PUSTAKA}

Assauri,Sofian. 2015. Manajemen Pemasaran. Jakarta: Rajawali Pers

Dian, Puspitarini. 2013. Pengaruh Faktor Kebudayaan, Sosial, Pribadi Dan Psikologi Terhadap Proses Keputusan Pembelian Produk Pizza (Studi Pizza Hut Cabang Jalan Jenderal Sudirman No.53 Yogyakarta). Skripsi. Universitas Negeri Yogyakarta

Engel, James F., Roger D. Blackwell, Paul W. Miniard. 2015. Perilaku Konsumen.Terjemahan F.X. Budianto. Jakarta:Binarupa Aksara

Kotler, Philip dan Gary Amstrong. 2015. Prinsip-prinsip Pemasaran. Edisi Kedelapan. Terjemahan Damos Sihombing. Jakarta : Erlangga

Kotler, Philip. 2015. Manajemen Pemasaran. Jilid 2. Jakarta : Bumi Aksara 
p-ISSN 2798-0499 e-ISSN 2798-0502

Mahendra, Giri. 2014. Pengujian Hipotesis dengan Uji Koefesien. Diunduh dari http://girimahendera.blogspot.com /2015/05/pengujian-hipotesisujikoefesien.html [diakses pada tanggal 22 november 2020

Mowen. H. 2017. Perilaku Konsumen. Jilid 1. Penerbit. Yogyakarta : Andi

Nurzam, N., Fauziah, R. S., \& Susena, K. C. (2020). PEGARUH HARGA DAN KUALITAS PRODUK TERHADAP KEPUTUSAN PETANI MEMBELI BIBIT SAWIT DI PT. BIO NUSANTARA TEKNOLOGI BENGKULU. EKOMBIS REVIEW: Jurnal IImiah Ekonomi dan Bisnis, 8(1), 79-89.

Priansa, Donni Juni.2016.Perilaku konsumen.Bandung:Alfabeta

Sugiyono. 2016. Metode Penelitian Kuantitatif Kualitatif dan R\&D. Cetakan ke-18. Bandung : Alfabeta

Sujarweni, V. Wiratna. 2020. Metodologi Penelitian (Lengkap, Praktis, dan Mudah Dipahami). Yogyakarta : PUSTAKABARUPRESS

Sunarto. 2016. Prinsip-prinsip Pemasaran. Yogyakarta : AMUS

Tjiptono. 2016า. Pengaruh Citra Merek, Kualitas Produk, Harga Dan Promosi Terhadap Keputusan Pembelian Iphone Di Kota Banda Aceh. Universitas Muhammadiyah Aceh

Winda, Risma. 2019. Faktor-Faktor Yang Mempengaruhi Keputusan Pembelian Online Pada Toko Nanda Colection Kabupaten Kaur. Skripsi. Universitas Dehasen Bengkulu 